\title{
MULHERES NEGRAS: BARREIRAS RACIAIS E ASCENSÃO SOCIAL NAS TRAJETÓRIAS DE DIRETORAS
}

\section{BLACK WOMEN: RACIAL BARRIERS AND SOCIAL RISE IN THE TRAJECTORIES OF TEACHERS TO PRINCIPALS}

\author{
Aleida Cardoso Corrêa \\ Prefeitura Municipal de Tubarão SC \\ Tânia Cruz \\ Universidade do Sul de Santa Catarina - UNISUL
}

\section{RESUMO}

Esta pesquisa tem como objetivo geral compreender a trajetória de mulheres negras de professoras a diretoras nas escolas de educação básica de Tubarão/SC em sua dinâmica das relações sociais de gênero, raça e classe. Como objetivos específicos buscou: conhecer o percurso e o enfrentamento de mulheres negras dentro dos espaços de sociabilidade na escola e fora dela; investigar a trajetória acadêmica e profissional de diretoras negras na construção de suas identidades; analisar o processo de ascensão social da professora negra para cargos de direção na escola como um espaço de liderança e lugar de resistência nas relações de raça, gênero e classe. Pautou-se pelo materialismo histórico e dialético propostos por Thompson (1981) e Frigotto (1999); e os autores Thompson (1992) Guimarães (2003) Davis (2011;2016) bell hooks (1995;2019), Carneiro (2003a;2003b), Gonzalez (1982 ${ }^{\mathrm{a}}$;1982b;1985) e Gomes (2005). Como metodologia se utilizou a história de vida relacionada à trajetória de ascensão a partir de entrevistas com diretoras negras. Entre os resultados destacam-se a discriminação racial vivenciada no decurso de suas vidas e no espaço escolar, em contrapartida a uma forte autoestima e autoexigência como fios condutores e à visão da educação como espaço de mudança para mulheres negras.

Palavras-chave: Mulheres negras. Feminismo Interseccional. Raça. Relações de gênero Direção da escola. Educação básica.

\begin{abstract}
This research has as general objective to understand the trajectory of black women from teachers to principals in schools of basic education of Tubarão/SC in their dynamics of social relations of gender, race and class. As specific objectives it sought: to know the route and the confrontation of black women within the spaces of sociability at school and outside it; investigate the academic and professional
\end{abstract}


trajectory of black directors at building their identities; to analyze the process of the social ascension of the black teacher to management positions in the school as a space of leadership and a place of resistance in the relations of race, gender and class. The theoretical framework is anchored in Thompson (1981) and Frigotto (1999); and Thompson (1992), Guimarães (2003), Davis (2011;2016), bell hooks (1995;2019), Carneiro (2003a;2003b), Gonzalez (1982a;1982b;1985), and Gomes (2005). The methodology used was the life story related to the ascension trajectory based on interviews with black directors. Among the results, the racial discrimination experienced in the course of their lives the school space stands out, in contrast to a strong self-esteem and self-demand as guiding threads and education as a space for change for black women.

Key words: Black women. Intersectional feminism. Race. Gender relations. School government. Basic education. 


\section{INTRODUÇÃO}

“[...] a gente nasce preta, mulata, parda, marrom, roxinha... mas tornar-se negra é uma conquista" (Lélia Gonzalez).

A temática aqui analisada, a presença de diretoras negras na rede pública de educação, insere-se em uma escrita-denúncia. Todas nós, mulheres negras, de alguma forma somos carregadas de ancestralidade e quando compreendemos a história buscamos nossa autoafirmação racial e feminina em diferentes espaços. Ao tomar consciência da rejeição estrutural do racismo desde cedo, evidencia-se para nós "que nem todas as mulheres são iguais”, pois somos desqualificadas e invisibilizadas no nosso modo de existir. Nesses processos de subjugação somos ainda submetidas ao estereótipo de não intelectualizadas, o qual bell hooks ${ }^{1}$ (1995) questiona para reafirmar: sim, somos capazes de produzir conhecimento!

Todavia, o Brasil do século XXI nunca esteve tão próximo do que se pensava sobre as pessoas negras no início do século XX, dado o pouco avanço rumos aos direitos reais implementados pelo ressurgimento do racismo antes parcialmente oculto. Tais políticas raciais seculares flertam, portanto, com as políticas educacionais neoliberais contemporâneas que manipulam propositadamente uma narrativa de que os direitos e oportunidades são iguais para todos sem distinção e que não se deve fazer políticas afirmativas na educação superior.

Os dados mostram que a permanência da mulher negra nas universidades brasileiras já é um grande desafio: apesar de constituírem 25\% da população, sua presença é irrisória, seja como alunas e professoras nas universidades, ou como pesquisadoras ou sujeito das pesquisas. Nesse sentido, há uma urgência em desmistificar esses espaços que continuam desiguais, e conhecer mulheres com formação superior, com suas formas de ascensão social e representatividade (SILVA, 2003).

\footnotetext{
${ }^{1}$ Pseudônimo de Gloria Jean Watkins e é escrito assim em minúsculo por desejo da própria autora. Por opção epistemológica incluímos para as autorias o prenome sempre que houver conteúdos citados pela primeira vez e nas referências finais.
} 
Entendemos que diretoras negras entrevistadas por uma professora e pesquisadora negra, contribui para a intersubjetividade e protagonismo racial negro, pois esse saber combate o epistemicídio sistêmico que circunda nossa intelectualidade. Grada Kilomba (2010, p.177) nos sinaliza que "a tomada de consciência surge a partir de quando a mulher negra adquire o processo de 'tornar-se sujeito', procura trazer a realidade do racismo diário, contado por mulheres negras baseado em suas subjetividades e próprias percepções” em um discurso contra-hegemônico de identidade racial, diríamos nós.

Para Oliveira (2004, p. 57), "a identidade racial/étnica é o sentimento de pertencimento a um grupo racial ou étnico, decorrente de construção social, cultural e política”. Esse conceito apresenta o elemento de luta contra um sistema que historicamente mantém essas populações subalternizadas. Movimentos negros não pensam raça de maneira biológica, e sim sociopolítica, e questionam o uso da ideia de cor em suas nuances embranquecedoras. A historiadora e antropóloga Lilian Moritz Schwarcz expressa o problema teórico da cor porque,

\footnotetext{
Afinal, estabelecer uma 'linha de cor' no Brasil é ato temerário, já que essa é capaz de variar de acordo com a condição social do indivíduo, o local e mesmo a situação. Aqui, não é só dinheiro e certas posições de prestígios embranquecem assim como, para muitos a 'raça' transvertida no conceito 'cor', transforma-se em condição passageira e relativa (SCHWARCZ, 1998, p.182).
}

Na luta pela defesa da identidade racial coletiva, pensamos que a escola é um dos espaços que interfere diretamente no complexo processo de construção das identidades coletivas de estudantes no exercício das experiências adquiridas, e do papel chave que a presença negra em um lugar institucional de poder representa para toda comunidade escolar, mais do que os conteúdos programáticos, ideia em concordância com Guacira Lopes Louro (2001).

Partindo dessa contextualização, nos perguntamos sobre a experiência negra na direção escolar: de que maneira gênero e raça atuam como diferenciadores na trajetória de professoras negras que se tornaram diretoras? Quais os obstáculos encontrados para que essas professoras chegassem aos cargos de direção nas instituições escolares? Como avaliam suas trajetórias? 
A partir de um recorte de nossa dissertação ${ }^{2}$ trazemos como objetivo para esse artigo analisar a trajetória de professoras negras a diretoras nas escolas municipais de educação básica da cidade de Tubarão em sua dinâmica das relações sociais de gênero com recorte étnico-racial, particularmente em relação ao processo de ascensão social da professora negra para cargos de direção e os obstáculos e facilitadores desse processo.

Este trabalho de pesquisa foi desenvolvido tendo como base o materialismo histórico e dialético propostos por Thompson (1981) e Frigotto (1999); e autores/as, entre outros/as, como Thompson (1992), Guimarães (2003), Davis (2011;2016), hooks (1995;2019), Carneiro (2003a;2003b), Gonzalez (1982 ${ }^{\mathrm{a}}$;1982b; 1985), Gomes (2005) e Ribeiro (2017).

\section{PROCEDIMENTOS METODOLÓGICOS}

O processo de pesquisa não tem por objetivo apenas obter e ampliar conhecimento, mas auxiliar na compreensão da realidade, para um melhor embasamento sobre a complexidade do que nos rodeia e oferecer elementos para contribuir na sua transformação (GATTI, 2002). Através do referencial teórico do materialismo histórico e dialético aqui adotado, é possível refletir com Gaudêncio Frigotto (1999, p. 73) que:

[...] a dialética, para ser materialista e histórica, não pode constituir-se numa 'doutrina' ou numa espécie de suma teológica. Para ser materialista e histórica tem de dar conta da totalidade, do específico, do singular e do particular. Isto implica dizer que as categorias totalidade, contradição, mediação, alienação não são apriorísticas, mas construídas historicamente.

Esses elementos citados por Frigotto (1999) estão presentes em todas as etapas da pesquisa, sejam elas da produção de dados ou da análise. A contextualização histórica é fundamental em uma pesquisa que parte do materialismo histórico e dialético, pois situar historicamente o objeto da pesquisa permite a busca pela

\footnotetext{
${ }^{2}$ Artigo decorrente de recorte de dissertação intitulada XXX, na universidade XXX; agradecemos à CAPES, pelo apoio por meio de bolsa de pesquisa.
} 
compreensão da totalidade e apreensão do real em suas múltiplas conexões e processos de vir a ser, ainda que o real nunca seja compreendido completa nem definitivamente, pois as perguntas poderão ser diferentes e trazer evidências antes não vistas (THOMPSON, 1981). Para Frigotto "A dialética situa-se, então, no plano da realidade, no plano histórico, sob a forma de trama de relações contraditórias, conflitantes, de leis de construção, desenvolvimento e transformação dos fatos" (FRIGOTTO, 1999, p. 82). Nessa perspectiva, o uso desse método nos permite elucidar histórias de vida de professoras negras da educação básica por meio da análise das posições ocupadas por essas mulheres em espaços hegemônicos de poder e sociabilidade por meio da ascensão profissional no contexto de uma sociedade racista, patriarcal e capitalista.

A preocupação com as fontes orais por meio de narrativas de histórias de vida esteve ancorada na histórica oral temática. Segundo Paul Thompson (1992, p.44),

\begin{abstract}
a história oral é uma história construída em torno de pessoas. Ela lança a vida para dentro da própria história e isso alarga seu campo de ação. Admite heróis vindos não só dentre os líderes, mas dentre a maioria desconhecida do povo. [...] Traz a história para dentro da comunidade e extrai a história de dentro da comunidade. Ajuda os menos privilegiados, e especialmente os idosos, a conquistar dignidade e autoconfiança. Propicia o contato - e, pois, a compreensão - entre classes sociais e entre gerações. E para cada um dos historiadores e outros que partilham das mesmas intenções, ela pode dar um sentimento de pertencer a determinado lugar e a determinada época.
\end{abstract}

A história oral, portanto, possibilita a apreensão de experiências de um determinado indivíduo ou grupo de pessoas e pode contribuir com a mudança social do tempo presente, se tratada se por um viés crítico (THOMPSON, 1992). A produção dos dados por meio de memórias se constituem como produção de fontes históricas primárias. Todavia, como problematiza o historiador Edward Paul Thompson, o conhecimento histórico não é o mesmo que um compilado de memórias, cabendo ao historiador fazer as perguntas adequadas às evidências e se utilizar de contraposições de outras fontes para além da oralidade e em diálogo com a produção teórica já publicada (THOMPSON, 1981).

A cidade onde se dá a participação das diretoras negras em suas práticas educacionais é Tubarão, assim chamada desde 1870 porque TUBA-NHARÔ, que em tupi-guarani significa "pai feroz", era o nome que os habitantes nativos Carijós davam 
ao rio que cortava a cidade (VETTORETTI, 1992). Em 2015 possuía uma população estimada em 105.686 habitantes (IBGE, 2015) e se destacava como polo comercial e universitário em função da universidade presente na cidade e região. Assim como em tantas outras cidades de Santa Catarina, constituiu-se por uma forte influência de italianos e alemães. Ainda que boa parte da população tubaronense desconheça fatos históricos sobre a escravidão, desde 1842 chegavam pessoas escravizadas pelo porto de Laguna e entre os anos de 1872 e 1882, havia cerca de mais de 90 mulheres negras escravizadas com seus filhos espalhadas em propriedades rurais (VETTORETTI, 1992).

As entrevistas com diretoras negras sob o prisma da questão racial nos permitem, nesse pequeno recorte da totalidade, conhecer suas memórias e também um pouco da história das instituições em que estão inseridas.

Dados obtidos pela Fundação Municipal de Educação (FME) informam que, no ano de 2019, havia quarenta e oito unidades escolares municipais, sendo vinte Escolas Municipais de Educação Básica (EMEBs) e vinte e oito Centros de Educação Infantil (CEIs); e que nesse conjunto de espaços educativos, apenas seis mulheres negras exerciam a função de diretoras. Já a Gerência Regional de Educação em Tubarão (GERED), atual Coordenadoria Regional de Educação (CRE), responsável pelas vinte e cinco escolas estaduais da região, informou haver somente uma mulher negra no cargo de diretora escolar em 2019. Por isso, entrevistamos sete mulheres negras de diretoras de escolas públicas em Tubarão no ano de 2019, que assinaram o termo de consentimento e disponibilizaram seus nomes verdadeiros. 
Quadro I - Perfil das diretoras entrevistadas

\begin{tabular}{|l|l|l|l|l|}
\hline $\begin{array}{l}\text { Diretoras efetivas } \\
\text { (entrevistas de fev. a set. de 2019) }\end{array}$ & $\begin{array}{l}\text { Ida- } \\
\text { de }\end{array}$ & $\begin{array}{l}\text { Tempo } \\
\text { de } \\
\text { direção }\end{array}$ & Formação & $\begin{array}{l}\text { Indicação e/ou Eleição } \\
\text { antes ou em 2019 para } \\
\text { mandato 2020-2023 }\end{array}$ \\
\hline Ana Maria da Silva (municipal) & 55 & $\begin{array}{l}2015 / 2019 \\
(5 \text { anos) }\end{array}$ & Pedagogia & $\begin{array}{l}\text { Indicação (se aposentou } \\
\text { em 2019) }\end{array}$ \\
\hline Christiane Martins Mathias (municipal) & 45 & $\begin{array}{l}2005 / 2019 \\
(\mathbf{1 5} \text { anos) }\end{array}$ & Matemática & $\begin{array}{l}\text { Indicação; } \\
{ }^{*} \text { eleita em 2019 }\end{array}$ \\
\hline Jacyra M. Martins Machado (municipal) & 49 & $\begin{array}{l}2019 \\
(\mathbf{1} \text { ano })\end{array}$ & Pedagogia & $\begin{array}{l}\text { Indicação; } \\
{ }^{*} \text { eleita em 2019 }\end{array}$ \\
\hline Marajane Corrêa Bento (municipal) & 51 & $\begin{array}{l}2013 / 2019 \\
(7 \text { anos) }\end{array}$ & Pedagogia & $\begin{array}{l}\text { Indicação; } \\
{ }^{*} \text { eleita em 2019 }\end{array}$ \\
\hline Regina da Silva (municipal) & 48 & $\begin{array}{l}2018 / 2019 \\
(\mathbf{2} \text { anos) }\end{array}$ & Pedagogia & $\begin{array}{l}\text { Indicação; } \\
\text { *eleita em 2019 }\end{array}$ \\
\hline Rosa Lúcio de Lima (estadual) & 60 & $\begin{array}{l}2016 / 2019 \\
(4 \text { anos) }\end{array}$ & Pedagogia & $\begin{array}{l}\text { Eleição; } \\
{ }^{*} \text { reeleita em 2019 }\end{array}$ \\
\hline Rosilene Machado Ferreira (municipal) & 51 & $\begin{array}{l}2017 / 2019 \\
(3 \text { anos) }\end{array}$ & Pedagogia & $\begin{array}{l}\text { Indicação; } \\
\text { *eleita em 2019 }\end{array}$ \\
\hline
\end{tabular}

Fonte: Autoras (2019)

A trajetória das docentes como diretoras, todas elas efetivas na rede pública, expressa a possibilidade de rompimento com hierarquias solidificadas em cargos ocupados na educação por pessoas brancas, que nas últimas décadas têm sido em sua maioria mulheres. Norteamos as entrevistas com um roteiro semiestruturado sobre suas experiências de escolarização e como diretoras, ligadas ao trabalho em educação por meio de um recorte sobre classe, gênero e raça.

\section{MULHERES NEGRAS NO MERCADO DE TRABALHO}

Ao trazermos várias inquietações necessárias avaliamos o retrato desigual que mostra a mulher negra inserida nos piores indicadores sociais, o que expõe as barreiras à sua ascensão social e econômica e a necessidade de uma crítica contundente a um sistema sócio econômico que a insere como subalterna dentro do tripé raça, gênero e classe. O Instituto da Mulher Negra Geledés (2013), entidade do movimento feminista negro tem acompanhado e denunciado essa situação há anos. Todavia, as estatísticas seguem apontando que a mulher negra continua na base da pirâmide social (IBGEPNAD, 2018)

A educação tem se configurado, ao longo de décadas, como um dos espaços possíveis para as mulheres negras, ainda que apresente obstáculos raciais. No caso dos cargos de direção escolar, a escolha de dirigentes perpassa processos de aproximação 
com o sujeito político que os/as designam, muitas vezes, por relações políticas ou cobrando alinhamento futuro (VELLANES, 2004), modo observado também aqui entre as mulheres entrevistadas. O processo de eleição tem sido uma reivindicação dos movimentos pela educação democrática e tem provocado mudanças onde acontecem, sendo que em nossa pesquisa ambos os métodos apareceram como possibilidade de ascensão para as diretoras negras.

No que se refere à história das diretoras escolares no Brasil Louro (2002) e Angelo Ricardo Souza (2006) tratam em suas obras da pouca presença de diretoras mulheres (e diríamos menos ainda negras) na história da educação brasileira. Em Santa Catarina, exceção que confirma a regra, destaca-se a forte presença de Antonieta de Barros como deputada e uma das poucas diretoras negras em meados do século XX.

Historicamente, no que versa sobre as desigualdades nas relações de gênero e direção escolar feminina, muitas professoras passaram a exercer um cargo que antes era ocupado por um dirigente homem e consequentemente atrelado a uma cultura sexista (COSTA, 1998). Edilene Pereira (2008) já enfatizava que poucos eram (e ainda são) “os estudos que tratam das experiências de ascensão das mulheres negras no mercado de trabalho" (PEREIRA, 2008, p.35).

Encontramos apenas três estudos que de certa forma compõem nosso universo de reflexão ainda que apenas a terceira seja exatamente sobre nosso foco de estudo. Trazemos Suelem Cabral Caetano Araújo, com a dissertação de 2018 Mulheres Negras em cargos de Gestão na Prefeitura de Belo Horizonte: Trajetória Educacional e Profissional, em que analisou diferentes cargos de gestão que tinham em comum discriminações de raça e obstáculos profissionais para as gestoras negras. A autora Juliana de Souza Krauss, que escreveu a dissertação de 2012 Clotildes Lalau: $a$ trajetória da educadora e militante antirracista na cidade de Criciúma (1957-1987); essa professora, branca, destacou a história da primeira diretora negra concursada em 1960 que permaneceu até 1982 como diretora e que, junto com seu marido, dava “palestras na Sociedade Recreativa União Operária sobre a importância dos estudos para ascensão social das populações de origem africana” (KRAUSS, 2012, p.24) contribuindo com as organizações de resistência negra na cidade. Outra autora, Conceição Aparecida Garcia Brunelli (branca, professora depois eleita diretora) 
escreveu, em 2007, a dissertação Gênero, raça, discriminação: o tom da cor na direção da escola pública, na qual escreve sobre gênero, raça e discriminação na escola em Diadema/SP e cujo tema nos é o mais próximo; essa professora nos traz as memórias de cinco diretoras negras concursadas entre outras sessenta diretoras brancas da cidade, todas de origem pobre e entre 40 e 65 anos; a partir do que a autora chamou de ciranda de conceitos, observou entre as entrevistadas palavras-chave como competência, compromisso, orgulho, conquista, missão, vocação e dom, destacando as dificuldades raciais e importância para todas da ascensão social por meio da educação e de suas lutas centradas na educação.

Mas a presença de mulheres diretoras negras não significou ainda uma grande abertura para o conjunto de mulheres negras docentes, é um caminho a se trilhar. Constituiu-se, portanto, uma continuidade da estrutura desigual nos ambientes escolares, pois mesmo que majoritariamente mulheres se lancem nesse universo educacional, ele era, e ainda é, de predomínio branco. Em consonância com Denise Carreira (2013) e tantas outras obras sobre o racismo escolar encontramos no interior da escola práticas que fortalecem a segregação racial, fazendo com que as crianças, jovens e adultos que frequentam o espaço passem a encarar o racismo como prática naturalizada.

\section{FEMINISMO NEGRO E A INTERSECCIONALIDADE RAÇA, CLASSE E GÊNERO}

É preciso entender a historicidade do feminismo, sendo esse movimento político de articulação de luta, militâncias, desconstruções, fases e conquistas, e que não dialoga somente com uma vertente ideológica de pensamento. Seu impacto se expressa como um movimento de transformação, partindo da compreensão e evolução de cada período histórico e cultural, pautado na luta e demandas das mulheres que buscam pela autonomia e visibilidade. Engloba, portanto, destacar o empoderamento e a conquista pela igualdade de direitos, para todas/os que se alinham a múltiplos feminismos que se constituíram ao longo do tempo. 
Carla Cristina Garcia (2015, p.13), define o feminismo como "a tomada de consciência das mulheres como coletivo humano, da opressão, dominação e exploração de que foram e são objeto por parte do coletivo de homens no seio do patriarcado sob suas diferentes fases históricas”. Se esse pode ser um ponto comum ao feminismo, ele é mais do que isso, como a própria autora vai contar mais adiante ao trazer a cisão no feminismo branco entre feminismos liberais e anticapitalistas ainda no século XIX. Mas a categoria universal de mulheres esconde experiências de classe, raça e gênero muito diferenciadas dentro de um processo único de subordinação (VELASCO, 2012). Cabe ressaltar que tais movimentos feministas foram de extrema relevância, sobretudo, para a denúncia sobre a forma como as mulheres estavam sendo oprimidas pelo patriarcado e pelo capitalismo. Mas cabe ainda uma nova transformação no feminismo que incorpore a questão racial, que trazemos como a interseccionalidade, já observada na vasta obra das intelectuais Angela Davis e bell hooks.

Nessa perspectiva se reacende nos anos 2000 o conceito de interseccionalidade cunhado por Kimberlé Crenshaw (1989) teórica negra, feminista e defensora dos direitos civis norte-americanos, que o trouxe em 1989 tornando-se uma das principais estudiosas da teoria crítica interseccional. Na década de 1980, refletindo debates cruciais realizados no ativismo negro destacamos as obras Mulheres, Raça e Classe (DAVIS, 2016) e Eu não sou uma mulher? (hooks, 2019a), nas quais ambas apresentaram suas contribuições e críticas acerca da problemática da estabilidade homogeneizante da categoria "mulher", e a necessidade de se atentar igualmente às formas combinadas de diferenciações e desigualdades como raça e classe social, entrecruzando as experiências de mulheres.

Destacamos uma síntese de Davis, da qual partimos:

Claro que classe é importante. É preciso compreender que classe informa a raça. Mas raça, também, informa a classe. E gênero informa a classe. Raça é a maneira como a classe é vivida. Da mesma forma que gênero é a maneira como a raça é vivida. A gente precisa refletir bastante para perceber as intersecções entre raça, classe e gênero, de forma a perceber que entre essas categorias existem relações que são mútuas e outras que são cruzadas. Ninguém pode assumir a primazia de uma categoria sobre as outras (DAVIS, 2011, s/p). 
Mas acrescentaríamos: não se pode retirar nenhuma delas, pois as três dimensões compõem o universo das mulheres negras de modo indissociável. Carla Akotirene (2018) destaca que o termo demarca o

paradigma teórico e metodológico da tradição feminista negra, promovendo intervenções políticas e letramentos jurídicos sobre quais condições estruturais do racismo, sexismo e violências correlatas se sobrepõem, e criam encargos singulares às mulheres negras (AKOTIRENE, 2018, p.44).

O Feminismo Negro brasileiro, particularmente a partir de meados da década de 1980, busca por meio de suas lutas construir novas visões de mundo na formação de grupos e redes articuladas, propondo que raça, classe e gênero criem o caminho político para a denúncia da opressão e desigualdade3.

\section{MEMÓRIAS DE DIRETORAS NEGRAS}

Para este artigo, organizamos as subseções em três tópicos: As dificuldades da ascensão e a questão racial; Práticas de segregação, autoafirmação racial e o colorismo; e Raça, classe, gênero e consciência crítica.

\subsection{AS DIFICULDADES DA ASCENSÃO E A QUESTÃO RACIAL}

Nos últimos anos a discussão sobre a condição da mulher negra brasileira nunca foi tão relevante em uma sociedade que sempre dificultou a superação das desigualdades raciais e de gênero. Ao refletir sobre os múltiplos aspectos que impedem a mulher negra de ascender socialmente, observamos que o tripé raça, classe e gênero atuam em conjunto, mas no sistema público de educação o que mais obstaculiza é o racismo. Para Queiroz (1997), a mulher não branca busca, através da escolaridade, quebrar as barreiras étnicas da posição discriminatória em que se encontra. Ascender

\footnotetext{
${ }^{3}$ Foge aos propósitos desse artigo o aprofundamento sobre o feminismo negro, que se encontra na dissertação da qual este artigo decorre.
} 
socialmente, aqui entendido, significa um crescimento não só para melhores condições salariais e de trabalho, mas em espaços de poder social e poder de fala.

A mulher negra, quando se lança em cargos mais altos sente o impacto da exclusão ao ultrapassar tal barreira. Luiza Bairros (1991) comprova que nem sempre o aumento da escolaridade da mulher afrodescendente se traduz em maiores chances de competição com as brancas, pois a condição racial continua bloqueando sua vida social e profissional. Assumir um cargo na hierarquia escolar, mesmo havendo tantas professoras negras, não é tão significativo do ponto de vista econômico, mas projeta subjetivamente a ideia de que elas podem estar em lugares que ressignificam o protagonismo feminino negro em um espaço de poder sóciopolítico como a escola.

Rosa, que se tornou diretora desde o início por eleição demonstra a resistência inicial sem motivo aparente mas que ela presume racial e mesmo assim fez questão de se preparar mais para a disputa.

\begin{abstract}
[ela falava que] não eram as nossas diferenças de ideias [com o setor administrativo], ou a cor da minha pele que iria atrapalhar o andamento da escola. [...] E deu certo! Deu muito certo! [...]Graças a Deus houve a possibilidade de eleição, porque se fosse por nomeação eu provavelmente não aceitaria. Porque normalmente quando você vem indicada por alguém, você vai ter que estar atrelada e servindo a esse alguém. [...] E eu fui me preparar; eu fui fazer o curso de gestão, e coloquei meu nome à disposição, até porque eu sentia uma empatia muito grande de alunos, de professores, de pais que já demonstravam esse desejo que eu participasse, mas também era um desejo muito meu (Rosa).
\end{abstract}

Por fim, ao ser eleita, adquiriu uma legitimidade que sabia ser necessária ao processo e também em seu compromisso com quem a elegeu. A única mulher negra eleita na rede pública estadual composta por sessenta e cinco escolas. O atrelamento político no âmbito estadual que até aquele momento vigoraram e ainda aconteciam punham em cheque a autonomia e Rosa preferia o compromisso com a comunidade escolar. Todavia, mesmo eleita com apoio da maioria sempre haverá um racismo à espreita e a cobrança da performance. A conquista e prática das eleições começou no Brasil a partir das décadas de 1970 e 1980, e trouxe para a escola a disputa política, as divergências e os conflitos inerentes ao processo democrático; em discussão a questão da representatividade perante a comunidade escolar e a relativa autonomia do poder político municipal e estadual (BASTOS, 1999). 
Em Tubarão, as eleições municipais só aconteceram no ano de 2019 e a questão da indicação delas em todo o período anterior era sempre um risco a ser calculado pelas diretoras negras. Qualificar-se sempre, se preparar, ser a melhor, se desdobrar, e se cuidar dos perigos do racismo tornavam-se as armas da permanência.

\begin{abstract}
No momento das minhas atuações tinha sempre um olhar: 'Ah! No que isso vai dar'? Por conta das questões raciais, porque primeiramente é difícil tu se impor [pausa] diante de muitos pais, muitas mães. Mas eles ficavam esperando de mim, muito mais de mim como negra: uma boa fala, a palavra adequada, um jeito e qualquer deslize, a cor influenciava muito. [...] Acho que as mulheres negras, elas também se inferiorizam [pausa] eu acho, mas há o apagamento também, porque tu se sentes sozinha e a gente se fecha. [...] Mas agora que a gente se expõe através do conhecimento, da informação; o que te dá hoje ir num evento e num encontro e impor a nossa fala, é o preparo.[...]. Mas sempre estaremos na linha de frente, qualquer deslize, acabou pra gente, mas com o tempo tua atuação vai mostrando a tua capacidade, ainda mais Tubarão, que é extremamente racista (Ana Maria).
\end{abstract}

Terreno pantanoso, uma boa base política junto a comunidade também pode ser fundamental, como narra Jacyra em seu primeiro mandato tampão de um ano por indicação em Tubarão, mas segundo mandato pois vinha de outra cidade:

[...] eu sempre pensei assim que nós, negros, principalmente a mulher negra, tudo que nós formos fazer eu penso que nós temos que fazer bem feito. Eu sempre digo que nós temos que saber entrar e saber sair. E quando a gente se propõe em alguma coisa a gente tem que saber o que está fazendo, por quê? Porque a gente é desafiada pelos outros, a gente é testada, e nesse momento eu acho que a gente tem que saber por que veio, por que está ali, e o que quer fazer.[...] Foi um processo tranquilo, foi natural. Eu já fui gestora onde morava, onde meu marido era natural; minha família ser natural do lugar, isso me trouxe assim um grande ponto positivo, então eu não encontrei muita dificuldade. E também porque era uma comunidade que existia muitas pessoas de cor negra, muita mistura de raças, então essa experiência que já tive antes, me fortaleceu para dar continuidade em outra escola como diretora (Jacyra).

Todavia, parece haver contradição em sua reflexão, pois inicia afirmando que ser diretora em Tubarão foi difícil e depois conclui que foi tranquilo e natural, o sobreesforço já naturalizado, quem sabe. Na verdade, vir a ser diretora por nomeação apresenta elementos de desafio: se nomeação, o fato de ficar entre a política municipal e a comunidade escolar e também não conseguir mensurar o grau de aceitação real de sua negritude. Por isso, conhecer o racismo também era uma aprendizagem necessária para se manter no cargo. 
[...] fui convidada a ser diretora, pois a que era anteriormente se aposentou. Eu aceitei de imediato, mesmo sabendo dos riscos e da responsabilidade que seria direcionar uma creche.[...]. Mas com o passar do tempo, vi que a dinâmica era diferente. A cobrança, as observações a respeito do nosso trabalho ficaram mais evidentes; não pensei [que era] pelo fato de ser negra, mas no meu íntimo, vi que sim, eu era mais exigida que a anterior, segundo fala de pessoas que trabalham aqui. [...]Espero que, quando acontecer as eleições do qual irei sim me candidatar, que eu tenha um bom resultado e permaneça na direção. [...]. Sei de outras diretoras, assim negras como eu, que demoraram a serem aceitas por alguns. É difícil mesmo eles 'ingerirem' que estamos no comando de uma instituição. [...]Nós, em pleno século XXI, sofremos muito racismo; e pelo fato de ser mulher ainda há a questão de não se ter muito respeito, de não ser considerada capaz de realizar determinadas funções (Regina).

[...] Então, esses 4 anos ali, foram incríveis, mas eu já estive 3 anos em outro tempo, [fui] a primeira diretora CEI Recife, fiquei 3 anos lá. Então, foi a minha primeira experiência como direção, essa é a minha segunda vez que estou atuando na direção; e só que a outra vez que eu atuei, tinha toda essa coisa do racismo, mas eu acreditava que isso não era importante, eu precisava era atuar como diretora. E essa vez eu tive uma outra visão, que a gente também é capaz de fazer, de provar para mim, eu vou me esforçar pela minha capacidade. Também esse olhar o negro tem que ter, não de só se abaixar (Ana Maria).

Aceitação, cobrança e presença do racismo estão em permanente luta na vivência das diretoras, apesar de toda a satisfação que sentem em estar num trabalho tão almejado. Parece que a experiência de mais de um mandato torna o racismo mais claro para essas diretoras que vão se tornando experientes em conhecer a comunidade escolar e, ao mesmo tempo, se autoafirmando racialmente. A informação sobre outras colegas diretoras negras revela reflexões coletivas sobre o racismo e forma de fortalecimento para o embate. O exercício dessa luta permanente é reconhecido por Berth (2018), quando afirma não ser possível empoderar alguém senão a nós mesmos; mas servirmos de amparo aos processos de conscientização para outros indivíduos.

Christiane, diretora há mais tempo por indicação em diferentes escolas, nos faz pensar na longa trajetória de luta contra a sub-representação que busca mantê-las na esfera da subserviência e a (re)criação de si. A diretora negra mais antiga de Tubarão, precursora, vivenciou intensamente o peso do racismo.

[...] a gestão era algo que me seduzia. Sempre acompanhei minha mãe na escola como secretária e via toda aquela movimentação, e me fascinava. E aqui não foi minha primeira gestão, ou seja, foi no Francelino Mendes na época do Prefeito Stupp, no São João em 2005. Foi indicação política e não fui bem aceita. O peso que eu mais senti foi o preconceito. Para eles da comunidade ter uma professora negra [na direção] não soou bem e me colocaram a fazer um serviço burocrático no CME [Centro Municipal de Esportes]. Quando o Zé Santos [o Secretário de Educação na época] me ofereceu 
a vaga, eu aceitei e me posicionei perante os preconceitos que viriam até a minha pessoa. Estou há 15 anos, tenho muito orgulho de fazer parte de toda a transformação da escola Faustina e de me ascender como mulher negra e diretora da mesma. Todo o começo para nós mulheres negras em chegar em um local de trabalho sempre é muito difícil [pausa]; ainda mais o fato de tu chegar sendo diretora escolar daquela instituição. [...] E foram passando os dias, os meses, os anos e eu tive, como qualquer outra mulher negra que está nessa posição, de provar minha capacidade sempre em dobro, pois era constantemente colocada em prova. Hoje posso dizer que muitos foram obrigados a me aceitar nesse cargo (Christiane).

Dentro dessa estrutura submissão-ascensão e contranarrativas, observa-se saídas emancipatórias concretas de empoderamento para essas mulheres. Lorde (2012), em uma de suas obras, fala da importância de ascender e não se calar, pois o silêncio não vai proteger as mulheres negras.

Saber-se negra é viver a experiência de ter sido massacrada em sua identidade, confundida em suas perspectivas, submetida a exigências, compelida a expectativas alienadas. Mas é também, e, sobretudo, a experiência em comprometer-se a resgatar sua história e recriar-se em suas potencialidades (SOUZA, 1983, p.17-18).

Para a psicanalista Neusa Santos Souza, ser negro não é uma condição dada $a$ priori. É um vir a ser. Ser negro é tornar-se negro. Entre as entrevistadas, uma delas não apresentou qualquer obstáculo na ascensão profissional relacionado ao racismo, tendo sido nomeada muito jovem como Rosilene ou mesmo Marajane, que atribui sua aceitação à cor mais clara da pele e cabelos alisados.

A primeira vez que eu fui diretora da EMEB São Martinho foi uma coisa que eu nem esperava. Eu estava na metade da faculdade, daí estavam no momento lá que queriam mudar a diretora, [...] as diretoras da Secretaria de Educação perguntaram se eu queria...[...] e eu acabei aceitando e foi muito gratificante, até veio a me ajudar na Pedagogia [curso] (Rosilene).

Eu gostaria de ver mais, porque somos poucas negras [pausa], somos muito poucas em ocupar esses cargos, a gente vê poucas diretoras mulheres negras; eu gostaria sim de ver mais. A gente sabe que nem todas são bem aceitas, assim, eu pelo fato de ter a pele mais clara, ter essa cor, e as pessoas não me identificam como negra, talvez eu tenha tido mais facilidade de conseguir [...]. É difícil a gente ver aquela negra escura, com o cabelo crespo, são pouquíssimas, pouquíssimas mesmo. Não senti essa dificuldade, como eu te disse, é mais o meu íntimo em lutar assim, e marcar presença como mulher negra. Isso sempre foi uma luta íntima minha [pausa] em me identificar como mulher negra, porque as pessoas resistem a um sucesso de um negro, ou em ver um negro numa posição melhor, tu não és tão negro assim [...] (Marajane).

Ainda que não sofrendo diretamente, o racismo estrutural não lhe passa despercebido impregnado como está na questão estética, seja a cor da pele ou tipo de 
cabelo. No que se refere à identidade, a anulação do pertencimento étnico-racial passa por processos de embranquecimento ou negação de sua raça social. Prova disso se verifica nas dinâmicas em categorizar tons de pele do mais claro ao mais escuro como determinantes para o tratamento social. Mulheres negras de pele mais clara foram diferentemente lançadas como "mulatas", sendo colocadas como mais humanizadas. Todavia, a mulher negra de pele mais clara sofre por não compreender em que escala valorativa se encontra, pelo fato de viver em uma sociedade instável que reafirma essas representações estéticas como mais aceitáveis mas em situações extremas iguala a todas na negritude. O reenquadramento racial pelo outro não deixa de ser uma violência, mesmo que aparente não lhe atingir.

Sobre esse processo identitário Nilma Lino Gomes (2005, p. 49) argumenta que:

[...] a identidade negra se constrói gradativamente, num movimento que envolve inúmeras variáveis, causas e efeitos, desde as primeiras relações estabelecidas no grupo social mais íntimo, no qual os contatos pessoais se estabelecem permeados de sanções e afetividades e onde se elaboram os primeiros ensaios de uma futura visão de mundo. Geralmente, este processo se inicia na família e vai criando ramificações e desdobramentos a partir das outras relações que o sujeito estabelece. A identidade negra é entendida, aqui, como uma construção social, histórica, cultural e plural. Implica a construção do olhar de um grupo étnico/racial ou de sujeitos que pertencem a um mesmo grupo étnico/racial, sobre si mesmos, a partir da relação com o outro.

A possibilidade de ocupar espaços de poder perante uma coletividade numerosa aparece em suas narrativas como uma autodeterminação de força sempre buscada contra as incertezas sofridas diariamente no âmbito escolar. A racialidade que é construída na relação com outras pessoas negras, também se constrói na relação com o branco. E esse olhar pode ser marcado pelo colorismo em que a escala de cor caracteriza a medida do grau de racismo aplicado sobre o sujeito e mais faz sofrer do que divide as pessoas negras entre si. Daí vamos à outra categoria, a questão do colorismo nas escolas.

\subsection{PRÁTICAS DE SEGREGAÇÃO, AUTOAFIRMAÇÃO RACIAL E O COLORISMO}

Ser negro (a) em um país que reafirma o "mito da democracia racial" põe em xeque o pertencimento racial por conta da escala de pigmentação que é atribuída a cada 
pessoa negra; consta-se haver diferenciação no tratamento e nas oportunidades conforme a pessoa mais se aproxime do fenótipo do branco. A cor ocupa espaço de discussão no movimento negro e tem relação com a autoafirmação devido à crítica ao pertencimento racial ser usada como ofensa pelas pessoas brancas. Em Tubarão podemos destacar diferentes modos de ser negro(a) em sua história, um deles a partir da segregação, a exemplo dos clubes de brancos e negros criados na cidade, como em outras cidades de Santa Catarina; e a autoafirmação racial da negritude na luta contra as discriminações e busca do empoderamento, que convivia simultânea e contraditoriamente com as práticas de embranquecimento de pessoas negras a partir das nuances de cor.

As memórias de segregação sobre os clubes foram trazidas por Ana Maria, sobre os lugares proibidos.

\footnotetext{
Negra! Sempre me considerei negra! Sempre! Olha, eu nunca me deixei ser tocada pelo que as pessoas me diziam. Eu tinha ciência do valor que eu tinha, na minha família, tanto no local onde eu morava [...] porque Tubarão era muito cheio de preconceitos, lugares para gente ir, lugares para gente poder entrar [pausa] então a gente foi aprendendo a se manter nos lugares onde a gente se sentia melhor (Ana Maria).
}

Fazem parte da história de Ana lembranças do banimento inicial dos clubes sociais brancos da cidade ou uma divisão dentro deles com uma corda onde só se podia dançar com a permissão do presidente do clube, tempos mais tarde e relatados após a entrevista. Cabe um pouco dessa história aqui. Em 1931 foi fundada a primeira instituição designada como negra, chamada Sociedade Recreativa $1^{\circ}$ de Maio segundo Oliveira (2011), sócio patrimonial e autor do livro Memórias do Clube $1^{o}$ de Maio. Em 1957 ressurge a antiga Sociedade Outro Preto, que passa a ser a Sociedade Recreativa Cultural e Esportiva Cruz e Souza em consideração ao poeta e abolicionista negro catarinense João Cruz e Souza. Os clubes negros promoviam seus bailes de debutantes e elegiam a mais "bela negra de Tubarão", exaltando a estética e a beleza afro como forma de representatividade na sociedade negra tubaronense. Estudiosa das relações de gênero nos clubes negros Maria das Graças Maria (2012) problematiza que, "antes de ser discriminado racialmente, o homem negro faz parte do gênero masculino, portanto devidamente adestrado para a prática da superioridade”. As mulheres negras 
quando adentravam nesses espaços de sociabilidade cultural e social eram reconhecidas pela beleza afro, em uma manifestação de resistência à beleza branca mas, contraditoriamente, subordinavam-se ao patriarcado negro e branco que as transformava em objetos sexuais e estéticos.

A participação feminina na organização dos clubes negros em Tubarão só se deu por volta de 1997 em uma delas, quando, por decisão inédita do conselho deliberativo que depois levou à assembleia geral da entidade, decidiu-se fazer uma diretoria composta somente por mulheres, apesar da resistência inicial (OLIVEIRA, 2011). Para Carneiro (2003a) esse processo de emancipação das mulheres se consolida em meio à dinâmica contraditória de oportunidade e obstáculos, na busca de igualdade de direitos das mulheres negras, ganhando força e estabelecendo novos desafios.

Além de Ana Maria, ao serem perguntadas sobre sua autoatribuição de raça as diretoras enfatizaram esse pertencimento de modo categórico:

Eu me considero preta, de cor preta (Jacyra).

Eu sou negra, me considero negra (Rosilene).

Sou uma mulher negra, minha cor de pele me identifico como negra (Christiane).

Me considero, sem sombra de dúvidas, uma mulher negra (Regina).

Bem, eu nunca tive dúvida da minha questão racial, sempre me considerei uma mulher negra em qualquer espaço que eu adentrava. Minha saudosa mãe Margarida sempre deixou muito claro isso dentro de casa para mim [...] (Rosa).

Eu sou negra! [...] Dentro da minha família, sempre nos consideramos negros. Mas no convívio com as outras pessoas desde sempre, eu nunca fui considerada totalmente negra, e isso assim, em termos de identidade para mim, sempre foi muito confuso. [...]quando alguém se referia desde criança, eu tinha a referência da minha família sobre o que é ser negro, e defender a raça negra, mas no convívio na escola quando criança, na adolescência, e até depois de adulta, as pessoas não se referiam a mim como mulher negra (Marajane).

Cabe analisar que mulheres aqui destacadas em cargos de poder resistam ao embranquecimento social que atuou (e atua) como um pré-requisito para deslegitimar quem se considera negro(a) no Brasil e digam “Somos negras!”. Tivera que lutar contra o racismo nas escolas. A partir das contradições e negação de si, em um processo de 
empoderamento versus racismo, pode ocorrer um processo de aceitação de sua negritude, quando se autorreconhecem e fazem aflorar o sentimento de autoconfiança, às vezes pelo apoio familiar.

A diretora Marajane nos apresenta o colorismo, que entra como pano de fundo de sua fala de autoafirmação racial e compreensão de que há uma nuance de significados de cor no universo dos brancos. Tal processo já foi analisado por Gonzalez e Hasenbalg (1982), quando afirmavam que os caminhos utilizados pela ideologia do branqueamento a algumas pessoas negras buscam se contrapor à uma identidade racial coletiva. Ainda com Marajane, o racismo estrutural em sua mais pujante perversidade:

\footnotetext{
Sempre era como morena ou então, é aquela tal coisa: 'Ah, mas tu não és negra!' Quando alguém fala alguma coisa sobre negro, eu retrucava. E que as pessoas retrucavam, desmerecendo a minha cor [pausa]eu sempre falava: 'Eu sou negra!' [...]. E na certidão de nascimento, desde sempre questionei a minha mãe; a minha primeira certidão estava como 'parda', depois da enchente em 1974, ela teve que retornar, e fazer uma outra certidão, foi colocada cor 'branca'. Então, eu sempre questionei, eu nunca gostei, porque eu não conseguia me identificar direito. Minha última certidão de nascimento [pausa] aí eu peguei e pedi para ela, porque foi feita uma terceira certidão, para ela me colocar de cor 'negra' porque me considerava negra. E mesmo assim, foi colocada cor 'parda'! (Marajane).
}

Violência institucional pela atribuição externa do outro por meio do uso e abuso da categoria "cor", que opera em uma complexidade negligenciada na sociedade brasileira.

[...]Nunca discriminada entre 'aspas', porque a partir do momento em que sou chamada de 'morena', eu estou sendo discriminada [pausa], mas eu não sofro da mesma forma como uma professora mais escura com o cabelo carapinha; e eu vi, professoras mais escuras com cabelo carapinha serem discriminadas por pais sim! Até vir[um pai] falar que: 'a minha filha não aceita a professora [outra, não ela] porque ela é negra' para mim, ele não me identificando como negra! (Marajane).

Branca, morena, parda, negra nunca. Para se ter uma ideia da ideologia do branqueamento naquele período - a década de 1970, a artista Adriana Varejão narra em uma entrevista a criação de um projeto em 2018 sobre cores no Brasil. Além dos clássicos marrom bombom, jambo, mulata apareceram outros. As palavras de Leonor 
Amarante e Patrícia Rousseaux (2018, s/p) assim resumem o projeto crítico Povo de cores Infinitas durante a entrevista dada artista Adriana Varejão:

\begin{abstract}
Sua inspiração para o projeto Polvo nasceu nos anos 1990 em uma associação entre sua pesquisa sobre tintas para pintar a pele em suas obras e a leitura de um censo realizado pelo IBGE de 1976, mostrando que, ao serem perguntadas pela sua cor de origem, as pessoas chegaram a nomear 136 cores: "Acastanhada, agalegada, alvinha, azul-marinho, escura, bronze, cobre, cor de canela, cor de cuia, meio preta, lilás, amarelosa, puxa para branca, queimada de praia, pálida, branca melada, branca suja, sarará, morena bem chegada, enxofrada, burro quando foge, etc.”.
\end{abstract}

Pessoas negras, que por suas "tonalidades" experienciam cotidianamente, às vezes dentro de uma mesma família, o confronto entre quem é mais ou menos aceitável pelo grau de negritude na palavra da pessoa branca, criando ilusões de aceitação. Florestan Fernandes (1972) já criticava essa questão deturpada e de consequências desastrosas em sua obra O Negro no Mundo dos Brancos (1972), na qual advertia que, ainda que negros ascendessem socialmente, estes jamais deixariam de ser negros e seu branqueamento não os protegeria do racismo, pois ainda seriam vistos como inferiores aos brancos.

Antônio Sérgio Guimarães (2003) aponta que a categoria "cor" sempre se configurou como um critério de segregação para fins sociais, sendo um dos conceitos de mais difícil definição, pois por ser nativo é habitual e termina por ser naturalizado. Guimarães (2003) conclui sobre a necessidade de pesquisas sobre o colorismo e de ao entrevistar pessoas buscar-se não só os critérios do IBGE, mas sempre a autoatribuição dos sujeitos.

Um país que ainda sente a influência da colonização e estabeleceu critérios ideológicos ao favorecimento da miscigenação, como um ideário social imune de preconceitos conforme a cor que lhe é atribuída, ignora os traços e a ascendência africana. Mesmo que a população negra seja mais que a metade do conjunto, há ainda na segunda década dos anos 2000 uma dificuldade atravessada por séculos de anulação, em reconhecer que estamos em um país onde não há um consenso coletivo sobre quem é negro(a) de fato. 
Analisando essas dicotomias, as entrevistas corroboraram que na comunidade escolar o tom de pele mais escuro e características físicas marcantes, como lábios grossos, cabelo afro e nariz largo, sofrem mais discriminação. A crítica ao colorismo hegemônico é necessária pois denuncia como o racismo opera nas relações de poder no contexto atual, ao adotar critérios de classificação extremamente nocivos à população negra. A ação institucional sobre o registro de cor de Marajane, com a recusa a inseri-la como negra na escrita documental, expressa as contradições da falsa democracia racial brasileira, aplicada arbitrariamente pelo racismo estrutural nas relações sociais em suas mais diferentes expressões.

Em outras palavras, o colorismo não se baseia somente em questões estéticas, mas na forma de como esses "tons brasileiros" operam na identificação racial de cada pessoa em suas interações sociais, no campo da discriminação racial e das desigualdades. Colorismo nada mais é que a tentativa de apagar a história da nossa ancestralidade e de aniquilamento cultural de grande parte da população negra no processo de autoreconhecimento.

\subsection{RAÇA, CLASSE E GÊNERO E CONSCIÊNCIA CRÍTICA}

O Movimento de Mulheres Negras no Brasil é atualmente um dos mais expressivos do mundo e um dos maiores em performance de organização social, identitária e política, como realçou em várias entrevistas a filósofa e ativista norteamericana Angela Davis. O cenário que se estabelece hoje é totalmente diferente de anos atrás, pois as mulheres negras, diante de todo o aniquilamento em suas demandas, buscaram outras formas de se deslocarem desse paradigma excludente e se lançaram na luta antirracista, antissexista e anticapitalista. Mas há uma certa compreensão de que nem todas expressam essa consciência política e do quão nocivo é silenciar diante das opressões vigentes. Ao politizar as desigualdades de gênero, Gonzalez (1985b) já enfatizava que a tomada de consciência da opressão ocorre antes de tudo pela questão racial. Essa visão apontada pela historiadora denota uma reflexão a partir de como essas diretoras experienciavam o comprometimento com essas ações 
e com propósito da luta antirracista dentro desses espaços, trazendo a experiência como mulheres negras educadoras como a chave de suas atuações.

A incorporação ou não de um pertencimento racial é um processo histórico, que pode ser construído junto às crianças em suas famílias mas segue durante toda a escolaridade e vida adulta, em diferentes experiências sociais. Sentir-se negra(o) pode se dar na família conforme relatos anteriores ou em outros espaços de sociabilidade como a universidade:

[...]eu não tinha consciência racial, sempre me dei bem com todo mundo, elas, as colegas de curso, falaram que eu tinha a 'alma branca', foi onde eu questionei que alma não tinha cor e elas ficaram em silêncio, não questionando mais o assunto [pausa]. Creio que foi o ponto inicial para eu entender tudo isso (Regina).

Fui me sentir representada na caminhada, quando tive aula com dois professores - o Paulo Henrique, de Geometria, também professor de Matemática. Naquele momento eu me senti representada, pois ele falava da questão racial também. Na época o Professor Maurício já dava aula na Unisul, mas não me deu aula. [...] entre várias questões falava muito da Promoção da Igualdade Racial. [...] Foi ali que me identifiquei [pausa]. Tinha a professora Dóris, que era outra referência como mulher negra, mas não me deu aula (Christiane).

Expressões racistas como justificativa de não racismo como "a alma branca"; professores universitários questionando o racismo; professoras negras como referência antirracista, exemplo de protagonismo raro ainda hoje; modos diferentes de construção da consciência racial crítica.

A participação em movimentos sociais é um dos caminhos possíveis e tais experiências foram encontradas na narrativa de Rosa, a mais velha das diretoras, que situa sua trajetória nas atividades da Igreja nas lutas contra a ditadura ou de colegas de trabalho de esquerda:

[...] a gente fazia parte do grupo de jovens da Igreja Católica, a nossa formação, ela foi muito forte; que foi uma época que a gente viveu a ditadura.[...] então, eu sempre digo que eu tive o privilégio, enquanto ali no grupo de jovens, de ter padres que já tinham um posicionamento político muito forte, que nos levavam para debates, que discutiam a questão social e política do Brasil e, inclusive, com passeatas.[...]. Muitas vezes, nos debates que a gente estava, em algum tipo de encontro, eles sempre diziam: 'De repente, aqui nesse ambiente, tem alguém nos vigiando[...]pode ser que talvez eu não volte.' [...] Então, eu sempre digo que a minha formação política começou ali: quando eu estava no grupo de jovens. Depois eu fui trabalhar em Criciúma, e eu tive o privilégio de trabalhar com profissionais que tinham esses [inaudível], que viveram em Cuba, que viveram no Chile [pausa], eu tive um convívio com pessoas de muito conhecimento, intelectuais mesmo. Na verdade, eu nem abria a boca, nunca nem me 
atrevi, eu só ficava ouvindo, prestando muita atenção mesmo [pausa], histórias assim fantásticas de luta (Rosa).

Tais experiências da luta de classes produziram em Rosa uma visão crítica mas a palavra ainda não tinha vindo, mais tarde, quando viesse a ser diretora, certamente. Mas as experiências estavam lá, na memória.

Outros elementos compuseram a experiência de raça e classe enquanto vivência. As dificuldades decorrentes da pobreza, o se sentir minoria nos cursos de licenciatura e as críticas decorrentes do pertencimento racial foram aspectos marcantes nas narrativas.

[...] tenho consciência de que outras mulheres deveriam ter cargos melhores. Ainda sofremos muito com a questão da pouca escolaridade, e por perceber que as mulheres negras ainda ocupam lugares de domésticas em grande número em nosso país. Tira pela nossa cidade, eu observo muito ainda de mulheres que trabalharam e ainda trabalham em casa de família. Penso que somente o estudo que nos dá possibilidades maiores de crescimento profissional. Mesmo nossa profissão estar muito desconsiderada pelos que estão no governo, penso que devemos lutar para provarmos ao contrário, que a educação abre mentes e abre portas, principalmente para o negro (Regina).

Para Regina, o fato de ascender social e economicamente pelo estudo expressa a luta pela escolaridade como fator principal de mudança social e que permitirá ao conjunto de mulheres negras a ascensão social e econômica. Tal aspecto é mais importante para ela que o pertencimento de classe e lutas decorrentes; tornam-se combativas em sua luta pela educação, como diretoras.

O pertencimento de classe, ainda que mais sutil, aparece misturado com raça e gênero: como base para os marcadores estéticos dos modos de vestir das classes dominantes associados à categoria de cor, aumentam a pressão cotidiana no exercício da profissão.

[...]a gente percebe algumas pessoas quando chegam aqui na escola, eles procuram pela diretora, pelo diretor, às vezes estão falando comigo, mas parece ser impossível ser eu a diretora. Talvez porque eu não esteja no meio daquele padrão, porque normalmente muitos olham as diretoras, a gente, e vê a maioria das mulheres com muito salto alto, muito bem vestida, extremamente elegante. Nada contra, acho bonito, mas não é muito meu perfil; não é que eu venha desleixada, mas eu não correspondo àquele perfil. Para você ver, algum tempo atrás, tinha uma pessoa que trabalhava aqui conosco, e ela sempre era confundida como diretora [pausa] porque ela tinha todo esse perfil da roupa, do salto alto, das elegâncias, e perfil padrão: branca, olho azul [pausa], então as pessoas se dirigiam a ela como se fosse a diretora. [...] mas a gente se colocar 
de maneira dócil, mas firme, sempre com muita firmeza, e então aí a pessoa — 'Ah, é você?' Mas a gente não espera: 'Ah, é você'. Eu respondo: 'Sim, sou eu a Diretora Rosa, em que posso ajudar?' (Rosa).

Não raro os critérios se acoplam aos de seleção por classe social, que historicamente também estiveram ligados com determinadas profissões, como maioria das diretoras de classe médias ou dominantes que por longo tempo foram nomeadas e atuavam dentro do status quo de cargos nomeados por políticos e associados aos poderes locais. As sete diretoras negras compõem, dentro de 48 diretoras, uma exígua participação, ainda que se possa argumentar que a população negra em Tubarão também seja pequena, não tão pequena talvez entre as professoras, mas não localizamos esse dado na prefeitura.

A função de diretora escolar é, para essas mulheres, o reconhecimento de um longo processo de luta, tendo claro que a barreira racial estava presente.

[...] E aí, até chegar a ser diretora, percorri um caminho muito difícil, porque era muito trabalho e a gente, por ser negra, parecia que tinha que trabalhar em dobro, em triplo [...]. E quando eu cheguei a ser gestora pela primeira vez, [...] eu penso assim que foi por merecimento mesmo; porque na época não tinha eleição [...] (Jacyra).

Eu penso que quando a gente estuda muito e se dedica para algo, você precisa galgar espaços importantes. Minha motivação foi justamente essa, porque tudo foi na base do sacrifício para mim. Nada veio de mão beijada, aliás, até hoje mesmo eu ocupando esse cargo de diretora escolar, cada passo em falso, vou ser sempre julgada e subjugada. Portanto, eu faço com que cada dia que eu venho para cá seja motivo de resistência, de enfrentamento. Eu almejei estar nesse lugar [pausa] então, como qualquer outra pessoa, eu também mereço estar aqui como mulher negra, professora e ocupando o cargo de dirigente escolar (Christiane).

Quando me convidaram a ser diretora, eu não pensei muito; aceitei porque somos poucas [negras] a ocupar esses cargos e penso que somos tão capazes como qualquer outra pessoa branca que sempre ocupou. Pensei que agora é minha vez. E vou fazer por onde porque sei da minha capacidade por ter tido essa oportunidade (Regina).

E ser diretora é, para elas, uma possibilidade de ascensão que as motiva, ainda que haja um preço alto a se pagar pela autoexigência decorrente do racismo que segue vigilante. As falas de luta dessas mulheres, enquanto mulheres negras e pobres que ascenderam por intermédio da educação e são atuantes como diretoras escolares, trouxe pouca referência direta da experiência feminista negra. Sobre o ainda distante 
feminismo Sueli Carneiro (2003b) reflete que é possível pensar em uma identidade reivindicada pela mulher negra, que se constitui como sujeito histórico e político de uma determinada classe social contra o racismo e as limitações do feminismo branco. De nossa parte agregamos a necessidade de aprofundar a construção de um feminismo intersecional que seja antissexista, antirracista e anticapitalista que acolha a todas as mulheres e que as mulheres negras brasileiras se sintam representadas e tenham seu lugar de fala, com destaque para a obra de mesmo título de Djamila Ribeiro (RIBEIRO, 2017) referência negra nos anos 2020.

\section{O LUGAR DE FALA...OU À GUISA DE CONCLUSÃO}

O "lugar de fala", um termo que tem aparecido com frequência em conversas entre militantes de movimentos feministas negros e em debates na mídia, representa a busca pelas vozes negras a falarem por si, a manifestarem suas inquietações e serem protagonistas da própria história. A mulher negra, ao se apropriar desse conceito, surge como um contraponto ao silenciamento de fala de segmentos subalternizados por grupos privilegiados em espaços de debate público. O lugar de fala entraria como uma categoria política na urgência de promover novas narrativas contra-hegemônicas.

Nada mais adequado a uma pesquisa que se propôs a resgatar memórias de diretoras negras trazê-las aqui nas considerações finais (ainda que pareça não soar acadêmico), para com suas narrativas utilizarem esse "lugar de fala" para comentarem sobre se o têm.

Certamente! O que me dá essa certeza é o fato de ter sido eleita com a maioria dos votos dos pais e alunos, até na percentagem [pausa] e professores, mas de quem mais obtive votos na verdade foi de pais e alunos. [...] e eu sempre cheguei em todos os lugares me posicionando, sem medo, sem me acovardar, por conta da cor da minha pele, nunca. (Rosa).

Sim! É lógico que sempre tem uma ou outra resistente [pausa], mas assim, se Jesus não agradou a todos [pausa], mas não é nem o fato de agradar ou não, existe sim essa respeitabilidade e esse crédito à minha fala enquanto diretora (Marajane).

Preciso ter esse lugar! E também o ambiente sempre foi de muito respeito. Então, eu, como diretora, sempre tive meu espaço de fala (Ana Maria). 
Sim! Eu preciso sempre estar legitimando meu espaço. Eu estou ocupando ele, então, as pessoas que trabalham comigo têm total consciência sobre isso (Jacyra).

Percebo sim. Faço dele legítimo e todos que ali estão entendem o recado. Claro que de forma muito respeitosa (Regina).

[...] se elas me respeitam é porque sabem que não estou aqui para brincar. Nunca tive nenhum problema com ninguém, e tenho também que falar do trabalho que o [secretário] Professor Maurício vem fazendo na educação do município, porque as pessoas passam a entender o valor do negro também. Então, eu, como mulher negra, sinto que esse lugar de fala, para mim, é legitimado sim (Rosilene).

Embora a realidade por muitas vezes se configure opressora, a presença de mulheres negras na educação rompe inúmeras barreiras hegemônicas impostas a toda população negra brasileira. A área da educação, mesmo sendo desprestigiada socialmente, ressignifica para a mulher negra uma posição positiva de sua identidade, a qual foge da corporalidade imposta de trabalhos estejam somente ligados à subserviência ou de objetificação do corpo negro.

Indiretamente pode ser que, em suas singularidades, essas mulheres expressem ganhos decorrentes dos movimentos raciais e do feminismo negro das últimas décadas, de fácil acesso nas redes sociais e na última década em Tubarão. No entanto, resta pensar o quanto ainda precisamos caminhar para uma articulação entre mulheres profissionais da educação e movimentos sociais feministas negros: uma boa luta!

\section{REFERÊNCIAS}

AKOTIRENE, Carla. O que é interseccionalidade? 1. ed. São Paulo: Editora Pólen Livros, 2018.

ALMEIDA, Sílvio L. de. O que é racismo estrutural? Belo Horizonte (MG): Letramento, 2018.

AMARANTE, Leonor e ROSSEAUX, Patricia. Povo de cores infinitas. Arte! Brasileiros. 02 jul. 2018. Disponível em: https://artebrasileiros.com.br/arte/povode-coresinfinitas/ . Acesso em: o9 set. 2020.

ARAÚJO, Suelem C. C. Mulheres Negras em cargos de gestão na prefeitura

de Belo Horizonte: trajetória educacional e profissional. 2018. Dissertação (Mestrado em Educação) - Centro Federal em Educação Tecnológica de Minas Gerais, Belo Horizonte, 2018. 
BAIRROS, Luiza H. Mulher Negra: o reforço da subordinação. In: LOVELL, Peggy (Org.). Desigualdades raciais no Brasil contemporâneo. Belo Horizonte: UFMG/Cedeplar, 1991, 177-193.

BASTOS, João B. Gestão democrática da educação: as práticas administrativas compartilhadas. In: BASTOS, João Baptista (Org.). Gestão democrática. Rio de Janeiro: DP\&A, 1999. p. 7-30.

BERTH, Joice. O que é empoderamento? Belo Horizonte (MG): Letramento, 2018.

BRUNELLI, Conceição A. G. Gênero, raça, discriminação: o tom da cor na direção da escola pública. 2007. Dissertação (Mestrado em Educação) - Universidade Metodista de São Paulo - São Bernardo do Campo. 2007.

CARNEIRO, Sueli. Mulheres em movimento. Estudos Avançados, São Paulo, v. 17, n. 49, set./dez. 2003a. Disponível em:

http://www.scielo.br/scielo.php?script=sci arttext\&pid=S010340142003000300008. Acesso em: 16 set. 2019.

CARNEIRO, Sueli. Enegrecer o feminismo: a situação da mulher negra na América Latina a partir de uma perspectiva de gênero. In: ASHOKA EMPREENDEDORES SOCIAIS E TAKANO CIDADANIA (Orgs.). Racismos contemporâneos. Rio de Janeiro: Takano Editora, 2003b. p. 49-58. (Coleção valores e atitudes. Série Valores; n. 1. Não discriminação)

CARREIRA, Denise. Indicadores da Qualidade na Educação: relações raciais na escola. São Paulo: Ação Educativa, 2013.

COSTA, Ana A. As donas do Poder. Mulher e política na Bahia. Salvador: Coleção Baianas/ NEIM/FFCH/UFBA - Assembleia Legislativa, 1998.

CRENSHAW, Kimberlé. Demarginalizing the Intersection of Race and Sex: A Black Feminist Critique of Antidiscrimination Doctrine, Feminist Theory and Antiracist Politics. The University of Chicago Legal Forum, n. 140, p. 139-167, 1989.

DAVIS, Angela. As mulheres negras na construção de uma nova utopia. 12/07/2011, Portal Geledés - Instituto da Mulher negra. Disponível em:

https://www.geledes.org.br/as-mulheres-negras-na-construcao-de-uma-novautopia-angela-davis/. Acesso em: 12 jul. 2019.

DAVIS, Angela. Mulheres, Raça e Classe. Tradução de Heci Regina Candiani. 1. ed. São Paulo: Boitempo, 2016.

FERNANDES, Florestan. O negro no mundo dos brancos. São Paulo: Global Editora, 1972.

FRIGOTTO, Gaudêncio. O enfoque da dialética materialista histórica na pesquisa educacional. In: FAZENDA, Ivani. (Org.). Metodologia da pesquisa educacional. São Paulo: Cortez, 1999. p. 69-90.

GARCIA, Carla C. Breve história do Feminismo. São Paulo: Claridade, 2015. 
GELEDÉS. Instituto da Mulher Negra e Cfemea - Centro Feminista de Estudos e Assessoria. Racismo Institucional: Uma abordagem conceitual. Rio de Janeiro: Editora Trama Design, 2013.

GOMES, Nilma L. Alguns termos e conceitos presentes no debate sobre relações raciais no Brasil: Uma breve discussão. In: BRASIL. Educação anti-racista: caminhos abertos pela lei federal no 10.639/03. Brasília: MEC, CNE, 2005.

GONZALEZ, Lélia. Mulher Negra. Afrodiáspora, Rio de Janeiro, Ipeafro, v. 3, n. 6/7, p. 94-104, 1985.

GONZALEZ, Lélia. A mulher negra na sociedade brasileira. In: LUZ, Madel (Org.). 0 lugar da mulher: estudos sobre a condição feminina na sociedade brasileira. Rio de Janeiro: Graal, 1982a. p. 87-104.

GONZALES, Lélia; HASENBALG, Carlos. Lugar de Negro. Rio de Janeiro: Editora: Marco Zero, 1982b.

GUIMARÃES, Antônio S. Como trabalhar com "raça" em Sociologia. Educação e Pesquisa, São Paulo, v. 29, n. 1, p. 93-107, jan./jun. 2003.

HOOKS, Bell. Intelectuais Negras. Revista Estudos Feministas, v. $3,2^{\circ}$ semestre 1995 .

HOOKS, Bell. E eu não sou eu uma mulher? Mulheres negras e feminismo. 4. ed. Rio de Janeiro: Editora Rosa dos Ventos, 2019. ISBN-10: 8501117404.

IBGE. Instituto Brasileiro de Geografia e Estatística. Indicadores Sociais: uma análise das condições de vida da população brasileira 2014. Estudos e Pesquisas:

informação demográfica e socioeconômica, n. 34. Rio de Janeiro: IBGE, 2015. Disponível em: https://biblioteca.ibge.gov.br/visualizacao/livros/liv91983.pdf. Acesso em: 13 abr. 2019.

IBGE. PNAD - Síntese de Indicadores Sociais: análise das condições de vida da população brasileira, 2018. Disponível em: www.ibge.gov.br. Acesso em: 05 ago. 2019.

KILOMBA, Grada. Memórias da Plantação: Episódios de Racismo Cotidiano. Trad. Jess Oliveira. 1. Ed. Rio De Janeiro: Cobogó, 2019.

KRAUSS, Juliana de S. Clotildes Lalau: a trajetória da educadora e militante antirracista na cidade de Criciúma (1957-1987). 2012. Dissertação (Mestrado em Educação) - Universidade do Estado de Santa Catarina, Florianópolis, 2012.

LORDE, Audre. Irmã Outsider: Ensaio e Discurso. São Paulo: Editora Crossing Press, 2012.

LOURO, Guacira L. Mulheres nas salas de aulas. In: PRIORE, Mary Del (Org.). História das mulheres no Brasil. 5. ed. São Paulo: Contexto, 2002. p. 443-481.

LOURO, Guacira L. Gênero, sexualidade e educação: uma perspectiva pós estruturalista. 4. ed. Petrópolis: Vozes, 2001. 
OLIVEIRA, Amauri de. Memórias do Clube $1^{\circ}$ de Maio. Tubarão: Editora e Gráfica Copiart, 2011.

OLIVEIRA, Fátima. Ser negro no Brasil: alcances e limites. Estudos

Avançados.[online], São Paulo, v. 18, n. 50, jan./abr. 2004. Disponível em: http://www.scielo.br/pdf/ea/v18n50/a06v1850.pdf. Acesso em: 20 fev. 2019.

MARIA, Maria das G. Clubes e Associações de Afrodescendentes na Florianópolis das décadas de 1930 e 1940. Geledés Instituto da Mulher Negra. São Paulo, o3 set. 2012. Disponível em: https://www.geledes.org.br/clubes-e-associacoes-deafrodescendentes-na-florianopolis-das-decadas-de-1930-e-1940/.Acesso: 14 set. 2020.

PEREIRA, Edilene. Marias que venceram na vida: uma análise da ascensão da mulher negra via escolarização em salvador/BA. 2008. Dissertação (Mestrado em Ciências Sociais) - Pontifícia Universidade Católica de São Paulo, São Paulo, 2008.

QUEIROZ, Dalcele M. O negro na universidade. Salvador: UFBA, 1997.

RIBEIRO, Djamila. O que é lugar de fala? Belo Horizonte (MG) - Feminismos Plurais - Letramento: Justificando, 2017.

SCHWARCZ, Lilia M. Nem preto nem branco, muito pelo contrário, cor e raça na intimidade. In: SCHWARCZ, Lilia M. (Org.). História da vida privada no Brasil: contrastes da intimidade contemporânea. São Paulo: Companhia das Letras, 1998. v. 4. p. 175-243.

SILVA, Petronilha B. G. Aprendizagem e ensino das africanidades brasileiras. In: MUNANGA, Kabengele (Org.). Superando o Racismo na Escola. Brasília: MEC/SECAD, 2003. p. 155-172.

SOUZA, Ângelo R. de. Perfil da gestão escolar no Brasil. São Paulo SP: Pontifica Universidade católica de São Paulo, 2006. Tese (Doutorado em Educação)Pontifícia Universidade Católica de São Paulo, São Paulo, 2006.

SOUZA, Neusa S. Tornar-se negro: as vicissitudes da identidade do negro brasileiro em ascensão social. 2. ed. Rio de Janeiro: Edições Graal, 1983.

THOMPSON, Edward P. (1981). (1. ed. 1978) Miséria da Teoria ou um planetário de erros: uma crítica ao pensamento de Althusser. Rio de Janeiro: Zahar.

THOMPSON, Paul. A voz do passado: história oral. São Paulo: Paz e Terra, 1992.

VELASCO, Mercedes J. Construyendo puentes: em dialogo desde/com el feminismo negro. In: VELASCO, Mercedes J. (Org.). Feminismos negros. Una antologia.1. ed. Madrid: Mercedes Jabardo y Traficantes de Sueños, 2012.

VELLANES, Paulo de T. O Colégio Estadual Presidente Humberto de Alencar Castelo Branco na Memória Social dos Moradores de Periperi. 2004. Dissertação (Mestrado em Educação) - Universidade do Estado da Bahia, Salvador, 2004. 
VETTORETTI, Amadio. História de Tubarão: das origens ao século XX. Tubarão: Editora: Prefeitura Municipal, 1992.

\section{Sobre as autoras}

Aleida Cardoso Corrêa: Mestre pelo Programa de Pós-graduação em Educação PPGE Universidade do SUL de Santa Catarina - PPGE. E-mail:

cooppir.tb@gmail.com

Tânia Cruz: Professora Doutora em Educação pela USP/SP e professora do Programa de Pós-graduação em Educação - PPGE da Universidade do Sul de Santa Catarina - UNISUL. E-mail: taniamara.cruz@gmail.com 